\title{
Erratum zu: Mehr Markenkraft. Die andere Seite der Komplexität: nicht Kosten-, sondern Wachstumstreiber!
}

Gordon Euchler und Benjamin Pleißner

Erratum zu:

Kapitel 17 in: R. Ohnemus et al. (Hrsg.), Context-Marketing, https://doi.org/10.1007/978-3-658-34291-3_17

Trotz sorgfältiger Erstellung unserer Bücher lassen sich Fehler nicht vermeiden, daher weisen wir auf Folgendes hin:

Kapitel 17, S. 265: In der Beitragsüberschrift wurde „Kontextkomplexität“ zu „Komplexität“" korrigiert. 